\title{
Isolation and characterization of hepatic mast cells from cholestatic rats
}

\author{
Laura Hargrove ${ }^{1,4}$, Allyson Graf-Eaton 2,4, Lindsey Kennedy², Jennifer Demieville², Jennifer Owens², Kyle Hodges ${ }^{3}$, \\ Brittany Ladd ${ }^{3}$ and Heather Francis i, $^{1,3}$
}

Mast cells (MCs) are immune cells that release histamine and other mediators. MC number increases after bile duct ligation (BDL) and blocking mast cell-derived histamine decreases biliary proliferation. We aimed to isolate and characterize MCs from cholestatic livers. Rats were subjected to BDL starting at $6 \mathrm{~h}$ and up to 14 days. MC infiltration was evaluated by toluidine blue. BDL rats were perfused using standard collagenase perfusion. Following enzymatic digestion, tissue was passed through a fine gauge needle. Suspensions were incubated with MAb AA4, washed and incubated with goat antimouse-coated Dynal beads. MCs were stained with toluidine blue, and in isolated MCs the expression of FCERI and MC proteases was measured. The expression of histidine decarboxylase, histamine receptors, VEGF receptors, and TIE 1 and 2 was evaluated by qPCR. Histamine and VEGF-A secretion was measured in MC supernatants. MC purity was evaluated by CK-19, CK-8, albumin, VAP-1, and a-SMA expression. In vitro, cholangiocytes and HSCs were treated with isolated MC supernatants from $\mathrm{BDL}$ rats treated with either $\mathrm{NaCl}$ or cromolyn sodium (to block $\mathrm{MC}$ histamine release) and biliary proliferation and hepatic fibrosis were measured. MCs infiltrate the liver and surround bile ducts starting at day 2 . We isolated a virtually pure preparation of mature, functional MCs. TEM images reveal distinct secretory granules and isolated MCs secrete histamine. MCs express FCERI, chymase, tryptase, RMCP-I, and RMCP-II, but were virtually void of other cell markers. Biliary proliferation and fibrosis increased following treatment with $\mathrm{MC}$ supernatants from $\mathrm{BDL}$ rats $+\mathrm{NaCl}$ and these parameters decreased in cells treated with $M C$ supernatants from BDL+cromolyn sodium. In conclusion, we have isolated and characterized MCs from cholestatic livers. MCs regulate cholestatic liver injury and hepatic fibrosis. This tool provides a better understanding of the paracrine influence of mast cells on biliary/liver pathologies.

Laboratory Investigation (2016) 96, 1198-1210; doi:10.1038/labinvest.2016.89; published online 22 August 2016

The liver is composed of parenchymal (PC) and nonparenchymal cells (NPCs) and the most prominent cell type in the liver is hepatocytes that are targets of diseases such as hepatitis, non-alcoholic fatty liver disease, non-alcoholic steatohepatitis, ${ }^{1}$ and hepatocellular carcinoma. Hepatocytes occupy $\sim 70-85 \%$ of the liver's cytoplasmic mass and are responsible for the production of bile that is then modified by a second cell type of the liver termed cholangiocytes. ${ }^{2}$ Cholangiocytes are epithelial cells that line the bile ducts of the liver and represent $\sim 3-5 \%$ of the liver's cytoplasmic mass. ${ }^{3}$ Cholangiocytes are the target cells for diseases known collectively as cholangiopathies and include primary sclerosing cholangitis (PSC), primary biliary cholangitis (PBC), biliary atresia, and cholangiocarcinoma. ${ }^{4,5}$ In addition to cholangiocytes and hepatocytes, the liver is comprised of hepatic stellate cells, Kupffer cells, and sinusoidal and vascular endothelial cells. Each cell type plays a particular role in liver disease progression by both autocrine and paracrine regulatory mechanisms.

Mast cells are inflammatory cells that can be both residential to the tissue and recruited from the bone marrow during injury or in response to certain signals. Mast cells have been found within the liver during certain pathologies including PSC and PBC. ${ }^{6-8}$ By immunohistochemical staining, it has been shown that the number of mast cells found in the liver increase during injury or disease progression when compared with normal liver tissue. ${ }^{7,8}$ In humans, mast cells are distinguished as either mucosal- or connective

\footnotetext{
Digestive Disease Research Baylor Scott and White Health and Medicine, Temple, TX, USA; ${ }^{2}$ Central Texas Veteran's Health Care System, Temple, TX, USA and ${ }^{3}$ Texas A\&M Health Science Center (HSC) HSC College of Medicine, Temple, TX, USA

Correspondence: Professor HL Francis, Ph.D., Texas A\&M HSC College of Medicine Central Texas Veteran's Health Care System or Digestive Disease Research Center Baylor Scott and White Health and medicine, Academic Operations 1901S. Veterans Memorial Drive (151), Building 205, Office 1R52, Temple, TX 76504, USA.

E-mail: hfrancis@medicine.tamhsc.edu

${ }^{4}$ These authors contributed equally to this study.

Received 22 April 2016; revised 6 July 2016; accepted 8 July 2016
} 
tissue-derived and are marked by the proteases, chymase and tryptase. ${ }^{9}$ Chymase-positive mast cells indicate that they originate or reside in connective tissue, whereas both chymase and tryptase-positive mast cells indicate mucosal mast cells. Similar terminology is used in rodent models. Mast cells from connective tissue in rats are termed rat mast cell protease 1 (RMCP-1) and mucosal mast cells termed RMCP-2. ${ }^{10}$ Within the mast cells, there is a large amount of preformed mediators including histamine, which is released on activation of a mast cell. Traditionally, mast cell activation occurs via typical $\mathrm{IgE} / \mathrm{FC} \varepsilon \mathrm{RI}$ receptor binding, however, mast cells can also be triggered by the activation of the numerous ligands and G-protein-coupled receptors found on their surface including histamine receptors $(\mathrm{H} 1-\mathrm{H} 4) .{ }^{10,11}$ We have recently demonstrated that mast cell activation and chemoattraction occurs via a stem cell factor (SCF)/c-kit interaction during cholangiocarcinoma progression. ${ }^{12}$

During cholestatic liver injury, cholangiocytes proliferate and secrete numerous factors including histamine and vascular endothelial growth factor (VEGF). ${ }^{13,14}$ We have shown that histamine regulates cholangiocyte proliferation via autocrine signaling, which allows for cholangiocyte homeostasis to be maintained. ${ }^{15}$ During PBC and PSC, patients have increased amounts of circulating histamine in their serum $^{16}$ and in rats subjected to bile duct ligation (BDL; to induce cholestasis), both serum and cholangiocyte histamine release is increased. ${ }^{14,17}$ We have demonstrated that mast cells infiltrate the liver following BDL and that blocking mast cellderived histamine using cromolyn sodium decreases biliary mass, proliferation and histamine secretion. ${ }^{14}$ Further, human cholangiocarcinoma tumors exhibit large numbers of mast cells and cromolyn sodium decreases tumor growth. ${ }^{12}$ Based on these observations, we surmise that mast cells play an important role in liver pathology and because there are no successful techniques to isolate and examine intact mast cells from mature rat livers, our aim of this study was to isolate and characterize hepatic mast cells from cholestatic rodent livers.

\section{MATERIALS AND METHODS}

All chemicals and reagents were purchased from Sigma Aldrich unless otherwise indicated. Primers and PCR reagents were obtained from Qiagen (SABiosciences, Valencia, CA) and Bio-Rad. Histamine enzyme immuno-linked assay (EIA) kits were obtained from Cayman Chemical (Ann Arbor, MI). ${ }^{14,15}$ The antibody, Anti-Rat Mast Cells, clone AR32AA4 (MAb AA4) used to isolate hepatic mast cells was purchased from BD Biosciences (San Jose, CA), this antibody has been used by other groups to isolate mature mast cells from bone marrow and the peritoneal cavity. ${ }^{18,19}$

\section{Animal Model}

Because the number of mast cells in normal tissues is relatively low, ${ }^{14}$ we used male Fisher 344 rats (Charles Rivers, $150-175 \mathrm{gm})$ subjected to BDL. BDL surgeries were performed as previously described by us and according to full adherence to local Institutional Animal Care and Usage Committee at Baylor Scott \& White Health. ${ }^{14,20}$ Animals were killed beginning at $6 \mathrm{~h}$ post BDL and livers were collected at 6 and $12 \mathrm{~h}$, 1day and up to 14 days. Liver blocks were collected from the right, left, caudate, and quadrate lobes and immediately frozen or fixed in formalin prior to paraffin embedding.

\section{Verification of the Presence of Hepatic Mast Cells Following BDL}

Prior to isolation of mast cells, we performed toluidine blue staining in livers from normal rats and BDL rats $(6 \mathrm{~h}$ to 14 days post BDL) to verify the presence and localization of hepatic mast cells. ${ }^{12,14}$ To perform toluidine blue staining, paraffin-embedded livers were sliced $(4-5 \mu \mathrm{m})$ and deparaffanized prior to toluidine blue staining. A fresh stock solution of toluidine blue $\mathrm{O}(1 \mathrm{~g})$ dissolved in $70 \%$ isopropanol $(100 \mathrm{ml})$ was used to make a final working solution ( $\mathrm{pH} 2.0-2.5$ ) containing $5 \mathrm{ml}$ of toluidine blue stock solution mixed with $45 \mathrm{ml}$ of $1 \% \mathrm{NaCl}(\mathrm{pH} 2.3$ ). Slides were incubated for 2-3 min, washed in distilled water $(3 \times)$ and quickly dehydrated with $95 \%$ ethanol (ETOH) and $100 \%$ ETOH (10 dips each). After clearing with xylene $(2 \times, 3$ min each), slides were mounted with a coverslip and visualized using a light microscope. To determine if hepatic mast cells are in close proximity to intrahepatic bile ducts, we performed immunohistochemistry for the biliary marker, cytokeratin-19 (CK-19; 1:50) $)^{14,20}$ followed by toluidine blue staining and in selected sections performed double immunofluorescent labeling for CK-19 and the mast cell marker MAb AA4 (1:100) as described. ${ }^{14}$ Staining was visualized using a light microscope or Leica Confocal microscope.

\section{Isolation of Mast Cells}

In the development of our mast cell isolation technique, we adopted numerous experimental steps from the established technique for cholangiocyte isolation. ${ }^{17,20}$ Specifically, after incannulation of the portal vein in 14 days post BDL rats $(n=6)$, an enriched ethylene glycol tetraacetic acid (EGTA) solution was pumped into the liver to flush out blood followed by a standard calcium/magnesium/collagenase perfusion for $20-30 \mathrm{~min} .{ }^{20}$ Livers (suspended in $1 \times$ hanks buffered solution (HBS) were placed on an end-to-end rotator for $30 \mathrm{~min}$ at $4{ }^{\circ} \mathrm{C}$. Before enzymatic digestion, the biliary tree was gently scraped and PC and NPCs were collected and saved. The biliary tree was discarded and the PC and NPC fractions were combined and digested using a mixture of DNAse $(5 \mathrm{mg})$, Collagenase XI $(8 \mathrm{mg})$ and Hyaluronidase $(12 \mathrm{mg}$ ) dissolved in standard RPMI 1640 medium ( $25 \mathrm{ml} /$ liver) for $45 \mathrm{~min}$ in a shaking water bath at $37^{\circ} \mathrm{C}$. Following enzymatic digestion, any remaining tissue was passed through a 22 gauge needle $2 \times$ and a 19 gauge needle $2 \times$ and finally filtered through a $0.4 \mu \mathrm{M}$ nylon filter. Pre-coated goat anti-mouse $\operatorname{IgG}$ magnetic beads were 
obtained from New England Bio Labs (Cat \# S1431S, Ipswich, MA). The PC/NPC fraction was incubated with $40 \mu \mathrm{l}$ of the primary antibody, Purified Mouse Anti-Rat Mast Cells; Clone: AR32AA4; Cat \# 551770 (MAb AA4, Fisher Scientific/BD Biosciences $)+1 \mathrm{ml}$ of RPMI 1640 medium + a pinch of DNase ('magic') for $30 \mathrm{~min}$ on ice with gentle agitation followed by two washes with $1 \times$ HBS. To prepare beads (anti-mouse beads), $10 \mu \mathrm{l}$ of beads per tube were placed on the magnetic stand and washed $3 \times$ with $1 \times$ HBS and then placed in 'magic' solution to allow for a total of $1 \mathrm{ml}$ of bead mixture per tube. After addition of bead mixture, tubes were mixed gently and placed in ice bucket on shaker for 30 additional minutes. The number of mast cells was determined by counting the number of toluidine blue-positive mast cells in the total cell population before immunomagnetic separation and the number of toluidine blue-positive mast cells after separation. Counting was performed manually using a light microscope. This method allows for the identification of immature, mature and very mature mast cells without inducing mast cell degranulation. Supplementary Figure 1 depicts the workflow performed to isolate hepatic mast cells from rat livers.

\section{Morphological Evaluation of Hepatic Mast Cells}

Toluidine Blue Staining

Following magnetic bead binding, cell smears were made by placing $100 \mu \mathrm{l}$ of cells onto a glass slide and allowed to air dry. Cells were fixed with cold acetone (10 dips) prior to toluidine blue staining as described above. After clearing with xylene $(2 \times, 3 \mathrm{~min}$ each $)$, slides were mounted with a coverslip and visualized using a light microscope.

\section{Transmission Electron Microscopy}

Cell isolates were prepared for transmission electron microscopy (TEM) by being gently pelleted in a $1 \mathrm{ml}$ Eppendorf tube and resuspended in the following fixative: $2 \%$ paraformaldehyde $/ 2.5 \%$ glutaraldehyde $/ 100 \mathrm{mM}$ phosphate buffer (all EM grade). Cells were fixed for $1 \mathrm{~h}$ at room temperature with gentle rocking. After fixation, cells were pelleted and resuspended and centrifuged. Fixed cells were sent to Dr. Wandy Beatty (Washington University School of Medicine, St, Louis, MO) for TEM analysis and image collection. The morphological changes of cell and mitochondria were observed by TEM. A total of $1 \AA \sim 10^{6}$ of cells were collected
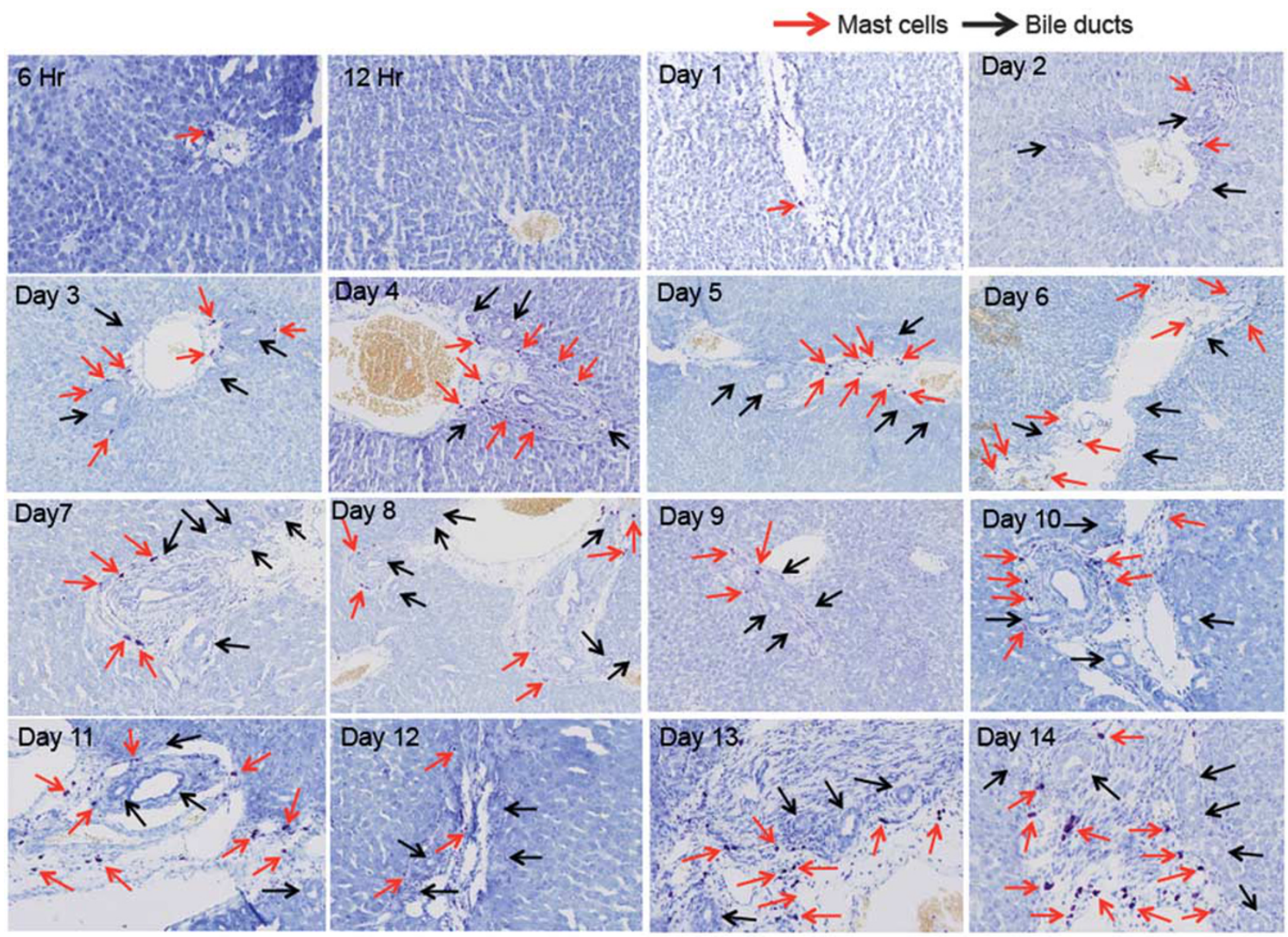

Figure 1 Mast cell infiltration in normal rats subjected to BDL. By toluidine blue staining mast cell infiltration was tracked from $6 \mathrm{~h}$ to 14 days post BDL. Mast cells were counted in right, left, caudate and quadrate liver lobes and were found in close proximity to bile ducts. Representative images for each time point collected are shown. Red arrows indicate mast cells and black arrows depict bile ducts. Images are $\times 10$ magnification. BDL, bile duct ligation. 
a

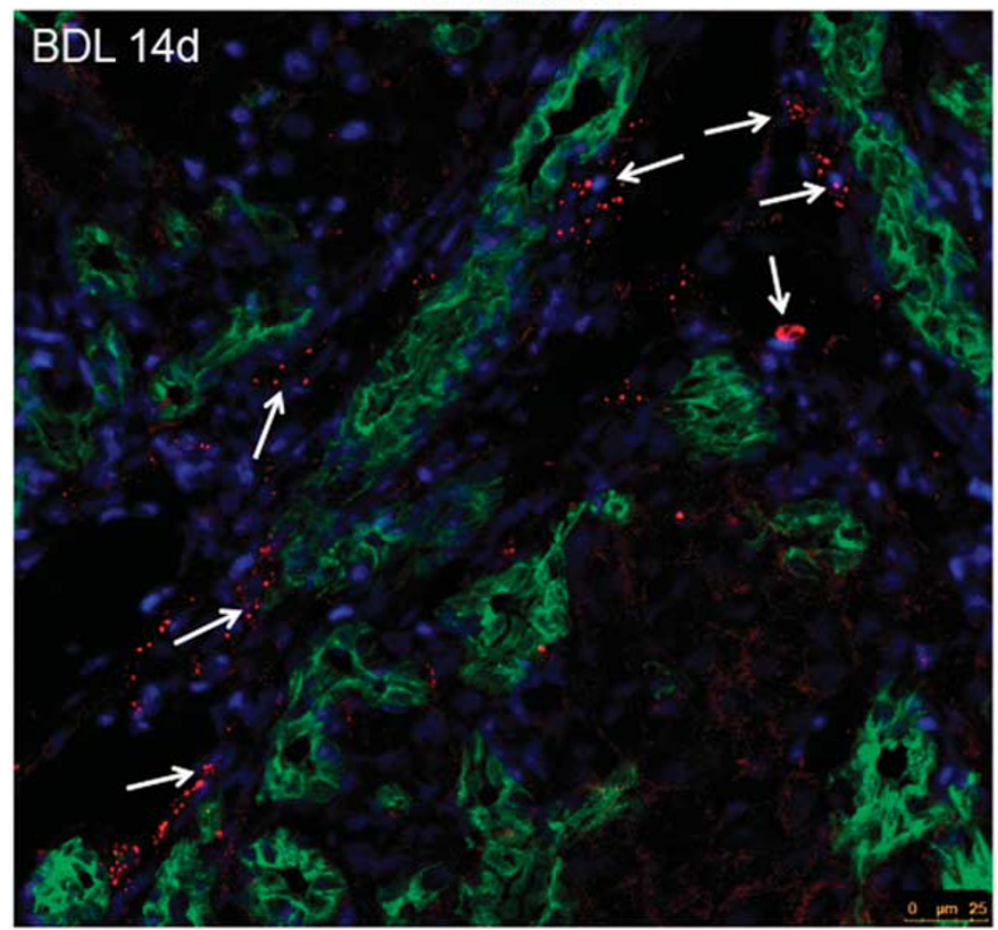

b

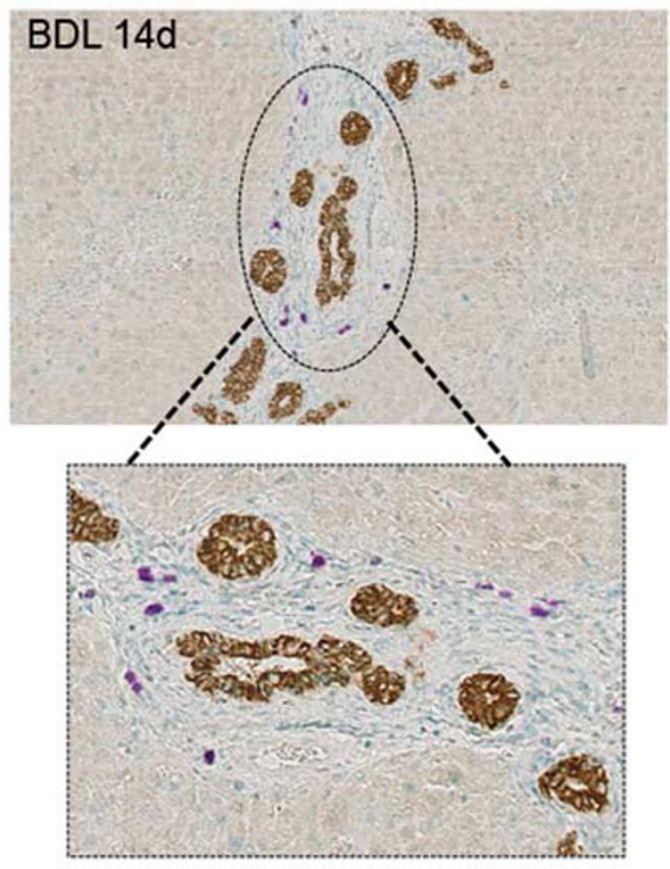

Figure 2 Localization of hepatic mast cells at BDL day 14. By immunofluorescence (a) and immunohistochemistry for CK-19 coupled with toluidine blue staining (b), mast cells are found in close proximity to bile ducts and not within the hepatocyte parenchyma. (a) Triple labeled immunofluorescence was performed in BDL 14 day liver sections for CK-19 (green), AA4 (red), and DAPI (blue); and mast cells are marked by white arrows. (b) Immunohistochemistry for CK-19 and subsequent toluidine blue staining show that mast cells are in close proximity to bile ducts and not found near hepatocytes (circled area is enlarged in the box). (Images are $\times 40$ (immunofluorescence) and $\times 10$ (CK-19/toluidine blue) magnification. BDL, bile duct ligation.

and subjected to fixation with $3 \%$ fresh glutaraldehyde and $1.5 \%$ paraformaldehyde solution at $4{ }^{\circ} \mathrm{C}$ for $1 \mathrm{~h}$, next to postfixation with $1 \%$ osmium tetroxide and $1.5 \%$ potassium ferrocyanide solution at $4{ }^{\circ} \mathrm{C}$ for $1.5 \mathrm{~h}$, then to dehydration with a graded series of ethanol solution, and finally to embed in Epon-618 after dehydration. Ultrathin sections were cut to stain with uranyl acetate and lead citrate, and observed under TEM (EM- 208 type, Phillips, WI, USA). The morphology of isolated hepatic mast cells was compared with cultured mast cells obtained from American Type Culture Collection (ATCC, Manassas, VA) that were fixed as described above.

\section{Characterization of Hepatic Mast Cells}

Cell isolates were evaluated for typical markers of mast cells and both PCs and NPCs by quantitative RT-PCR. ${ }^{12,14}$ We measured the expression of the specific mast cell markers including c-kit, FCER1, RMCP-I and -II, chymase, and tryptase. ${ }^{12,14}$ Immunofluorescence was performed in cell smears from isolated mast cells for the following: FceR1, chymase, and tryptase. Further characterization of mast cells was performed by measuring the expression of the following cellular markers: histidine decarboxylase (HDC), histamine receptors (H1-H4), VEGF receptors, VEGF-R2/R3 and angiopoietin receptors, Tie-1, and Tie-2 by real-time PCR or RT-PCR. ${ }^{12,14,15}$ Other cellular markers measured included

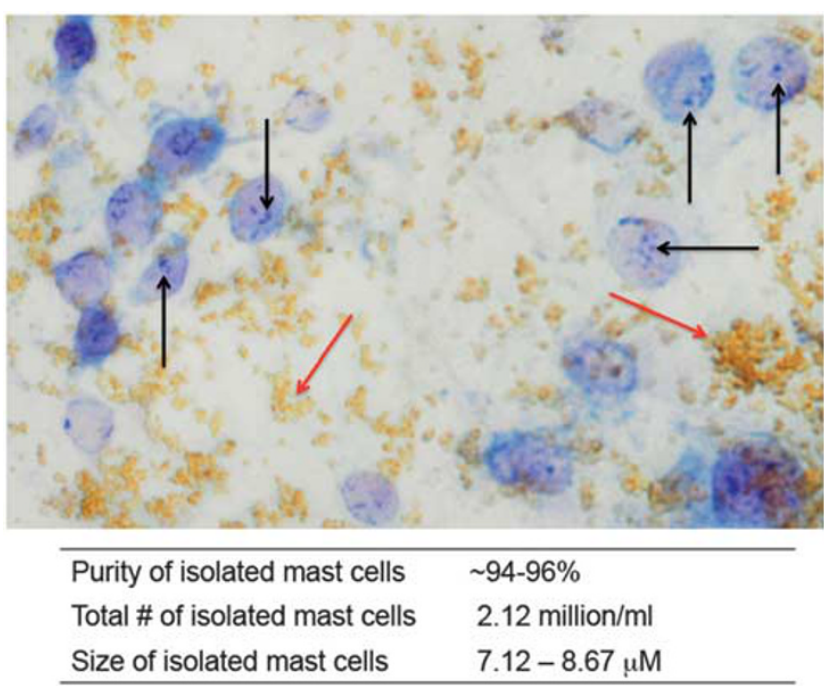

Figure 3 Isolation of hepatic mast cells from BDL post 14 days. By enzymatic digestion and magnetic bead binding a virtually pure population of mast cells was obtained from BDL rat liver day 14. Toluidine blue staining indicates a population of mature mast cells as shown by intact granules (black arrows, beads are indicated by red arrows). Image is $\times 20$ magnification. The purity of isolated mast cells $(\sim 95 \%)$ was determined by counting toluidine positive blue mast cells prior to bead attachment and after. The total number of isolated mast cells totaled 2.12 million $/ \mathrm{ml}$ and the average size was $8.2 \mu \mathrm{M}$. BDL, bile duct ligation. 
the cholangiocyte marker, CK-19, the hepatocyte marker, CK-8, vascular adhesion protein-1 (VAP-1), and $\alpha$-SMA (hepatic stellate cell marker). Real-time PCR was performed as described in $1 \mu \mathrm{g}$ of total RNA; GAPDH was used as a housekeeping gene. The expression of all markers in isolated hepatic mast cells was compared with total liver RNA. Immunofluorescence was performed as previously described in cell smears from isolated mast cells for CK-19 and CK-8 and visualized on a Leica Confocal Microscope.

\section{Evaluation of Histamine and VEGF Secretion From Isolated Mast Cell Supernatants}

To determine if isolated mast cells are functionally active, we treated mast cells with T-Cell Culture Supplement with conA (T-STIM, $100 \mu \mathrm{l} / \mathrm{ml}$ ) to induce degranulation and incubated cells at $37^{\circ}$ for $60 \mathrm{~min}$ prior to collecting supernatants. Histamine release was measured by EIAs (Cayman Chemical). ${ }^{14,15}$ Activated mast cells release numerous factors including growth factors like VEGF, ${ }^{21}$ therefore, we also evaluated VEGF secretion by EIA (Abcam, Cambridge, MA) in our isolated mast cells treated cells with T-Cell Culture Supplement with ConA (TSTIM, $100 \mu \mathrm{l} / \mathrm{ml}$ ) and incubated at $37^{\circ}$ for $60 \mathrm{~min}$.

\section{Detection of Mast Cells in Other Models of Liver Injury}

Toluidine blue was performed as described in liver sections from normal rats subjected to $70 \%$ partial hepatectomy $(\mathrm{PH})$ at 3 days and in normal rats fed taurocholic acid for 1 week. ${ }^{14,22,23}$ In human tissues from late-stage PSC patients with cirrhosis, we performed toluidine blue to detect mast cell infiltration. Human tissues were obtained by needle biopsies from PSC patients and were provided by Dr. Pietro Invernizzi
(Humanitas Research Hospital, Rozzano, Italy) under a protocol approved by the Ethics Committee of the Humanitas Research Hospital; the protocol was also reviewed by the local Veterans' Administration IRB and R\&D Committee. The use of human tissue was also approved by the Baylor Scott \& White Health Institutional Review Board.

\section{In vitro Evaluation of Mast Cell-Derived Histamine on Biliary Proliferation and Fibrosis}

Finally, to demonstrate that mast cells and mast cell-derived histamine can alter cholangiocyte response, cultured cholangiocytes were treated with isolated mast cell supernatants obtained from 14 day BDL rats treated with either sodium chloride $(\mathrm{NaCl})$ or cromolyn sodium (to block mast cell histamine release) $)^{12,14}$ and we measured (i) proliferation by MTS assay and inflammatory cytokine expression for IL-10 and TGF$\beta 1$ by real-time PCR. Further, to demonstrate that mast cells trigger a fibrogenic response, human hepatic stellate cells (HSCs) were treated with isolated mast cell supernatants obtained from 14 day BDL rats treated with either $\mathrm{NaCl}$ or cromolyn sodium and the expression of fibrosis markers such as fibronectin, collagen type-1a and $\alpha$-SMA were evaluated by real-time PCR.

\section{RESULTS}

Hepatic Mast Cell Numbers are Increased Following BDL and Found in Close Proximity to Bile Ducts

Following BDL, hepatic mast cells infiltrate the liver starting at day 2 and peaking at day 7 . After a peak at 7 days post BDL, a steady number of hepatic mast cells are found that continues from day 8 through day 14 . Representative images
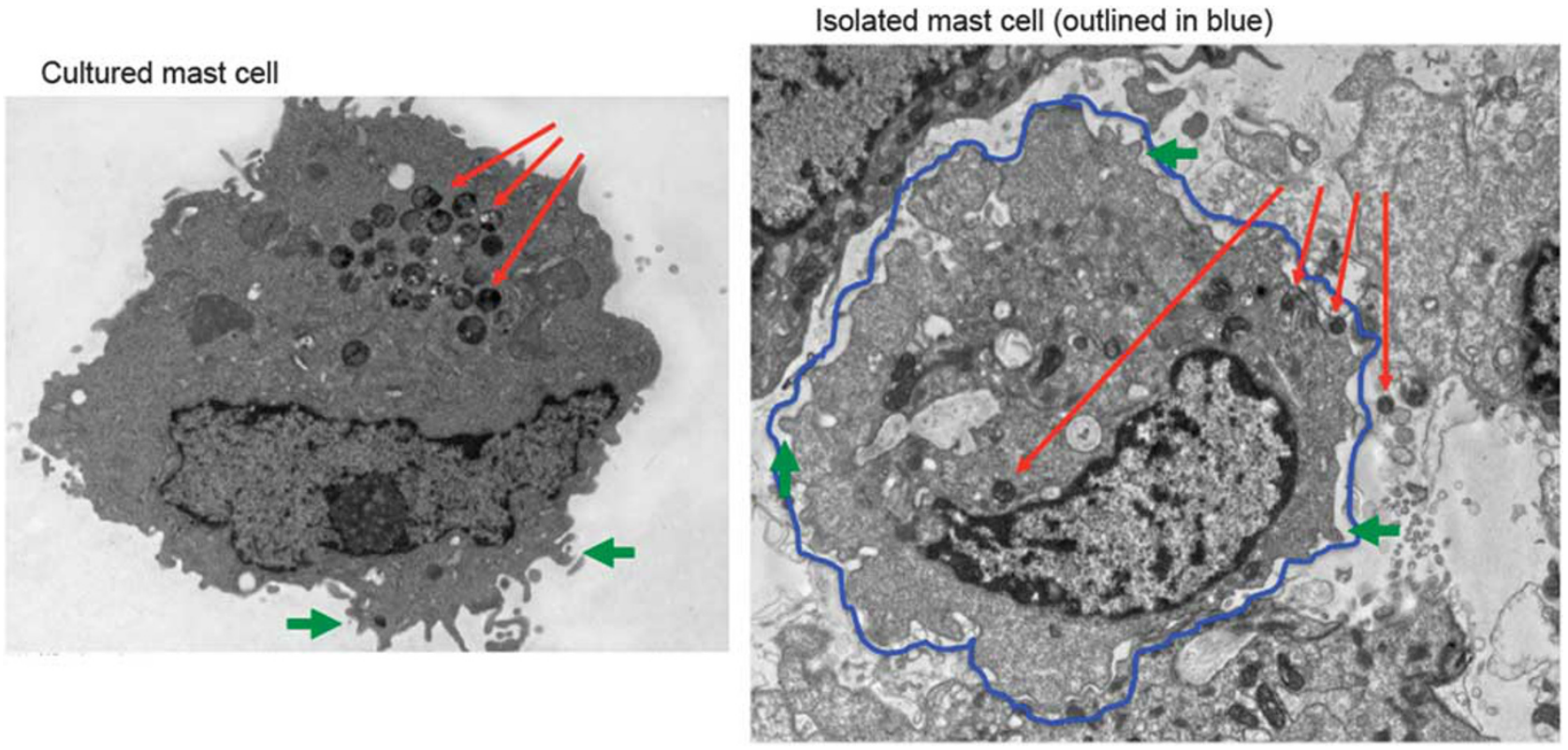

Figure 4 Characterization of isolated hepatic mast cells by transmission electron microscopy (TEM). TEM was performed in both cultured mast cells (left image) and isolated mast cell preparations (right image). Typical membrane folds (green) and granules (red) that are found in mature mast cells are seen in the isolated mast cell preparations. 
of mast cell infiltration are found in Figure 1 beginning at $6 \mathrm{~h}$ through day 14. Hepatic mast cells (red arrows) are found in close proximity to bile ducts (black arrows). Interestingly, mast cells do not appear until bile ducts begin to develop and this is coupled with an increase in ductal mass, suggesting that mast cells infiltrate the damaged liver to support the increased demand of the proliferating biliary epithelium. Supplementary Figure 2 graphically demonstrates the number of toluidine blue-positive mast cells both as average per lobe (four lobes counted) and in total mast cell number in all four lobes.

In BDL day 14 liver sections, we performed immunofluorescent staining for AA4 and CK-19 (Figure 2a) and immunohistochemistry for CK-19 coupled with toluidine blue staining (Figure 2b) and found that mast cells were in close proximity to bile ducts, but are not found within the hepatocyte parenchyma. These data demonstrate that mast cells infiltrate the liver following $\mathrm{BDL}$ and further provide the rationale to isolate hepatic mast cells from BDL rodent livers.

\section{Hepatic Mast Cells are Isolated From Liver Digests with MAb AA4}

Isolated mast cells were obtained from BDL rats at day 14 since this appears to be a time when the influx of mast cells has stabilized and the wound has healed in the bile duct and bile duct mass is steady. After enzymatic digestion and incubation with the specific mast cell antibody, MAb AA4, we isolated a population of intact mast cells as shown in Figure 3 by toluidine blue staining. The technique allows for the isolation of intact mast cells as noted by the multiple granules found within the mast cells (marked by black arrows, magnetic beads are marked by red arrows). The purity, number, and size of isolated mast cells obtained from BDL 14 day rats are provided in Figure 3.

\section{Characterization of Hepatic Mast Cells}

By TEM, isolated hepatic mast cells have a similar morphology when compared with cultured mast cells. Isolated mast cells (Figure 4, right image) display typical membrane folds (outlined in blue) indicated by the green arrows. Further, a

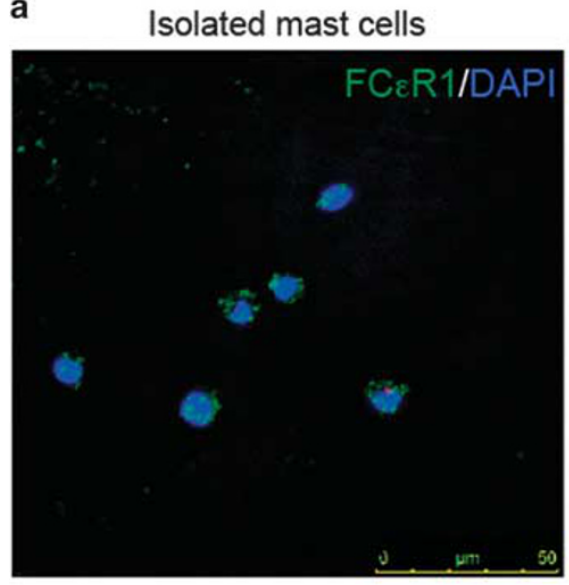

Isolated mast cells

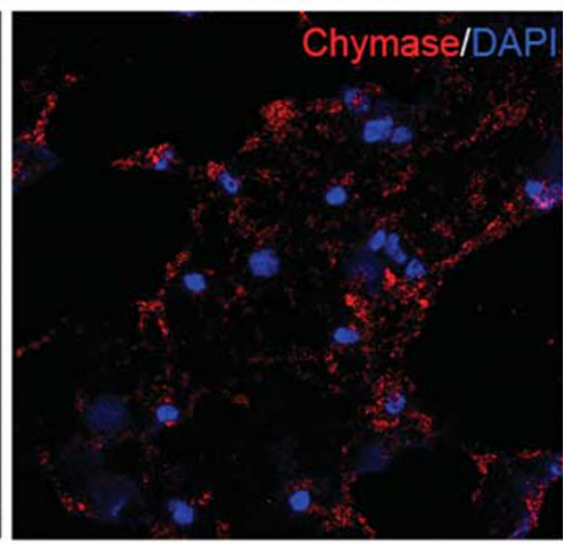

Isolated mast cells

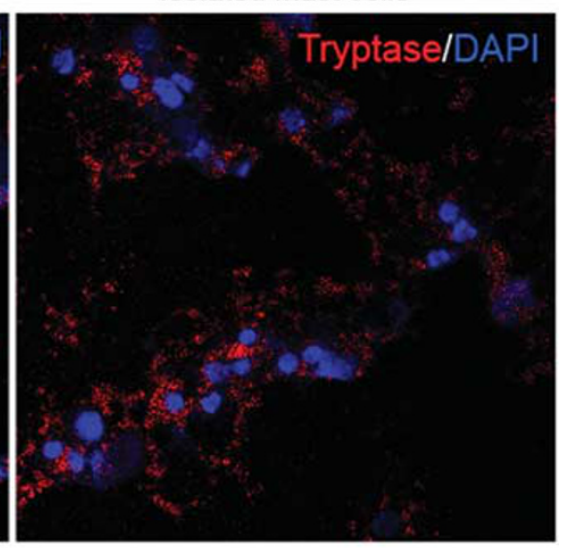

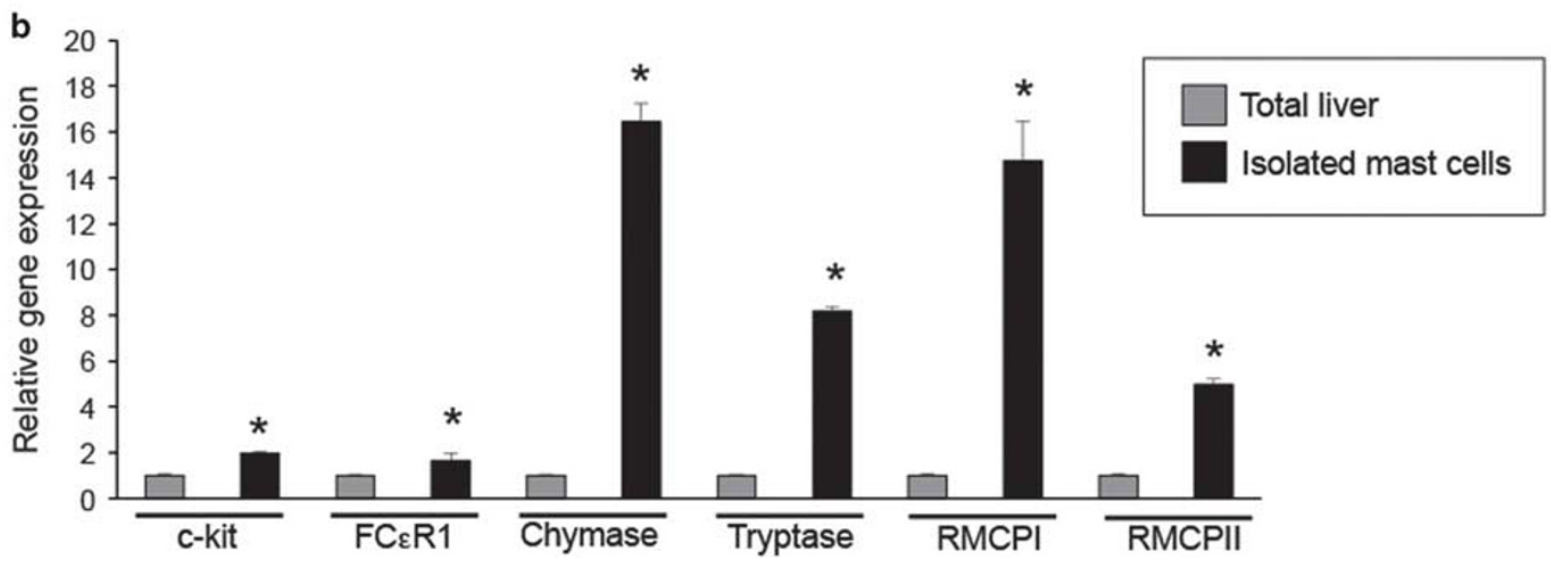

Figure 5 Characterization of isolated hepatic mast cells by (a) immunofluorescence and (b) real-time PCR for mast cell markers. (a) Double immunofluorescence was performed in cell smears from isolated mast cell preparations for the following markers: FCER1, chymase, and tryptase along with DAPI. Isolated mast cell preparations express FCER1, chymase, and tryptase. (b) By real-time PCR the expression of c-kit, FCeR1, chymase, tryptase, RMCP-I, and RMCP-II are upregulated in isolated mast cells compared with total liver RNA. Images were obtained on a Leica Confocal Microscope and are $\times 20$ magnification. Data are represented as mean \pm s.e. of six experiments. ${ }^{*} P<0.05$ versus total liver. 

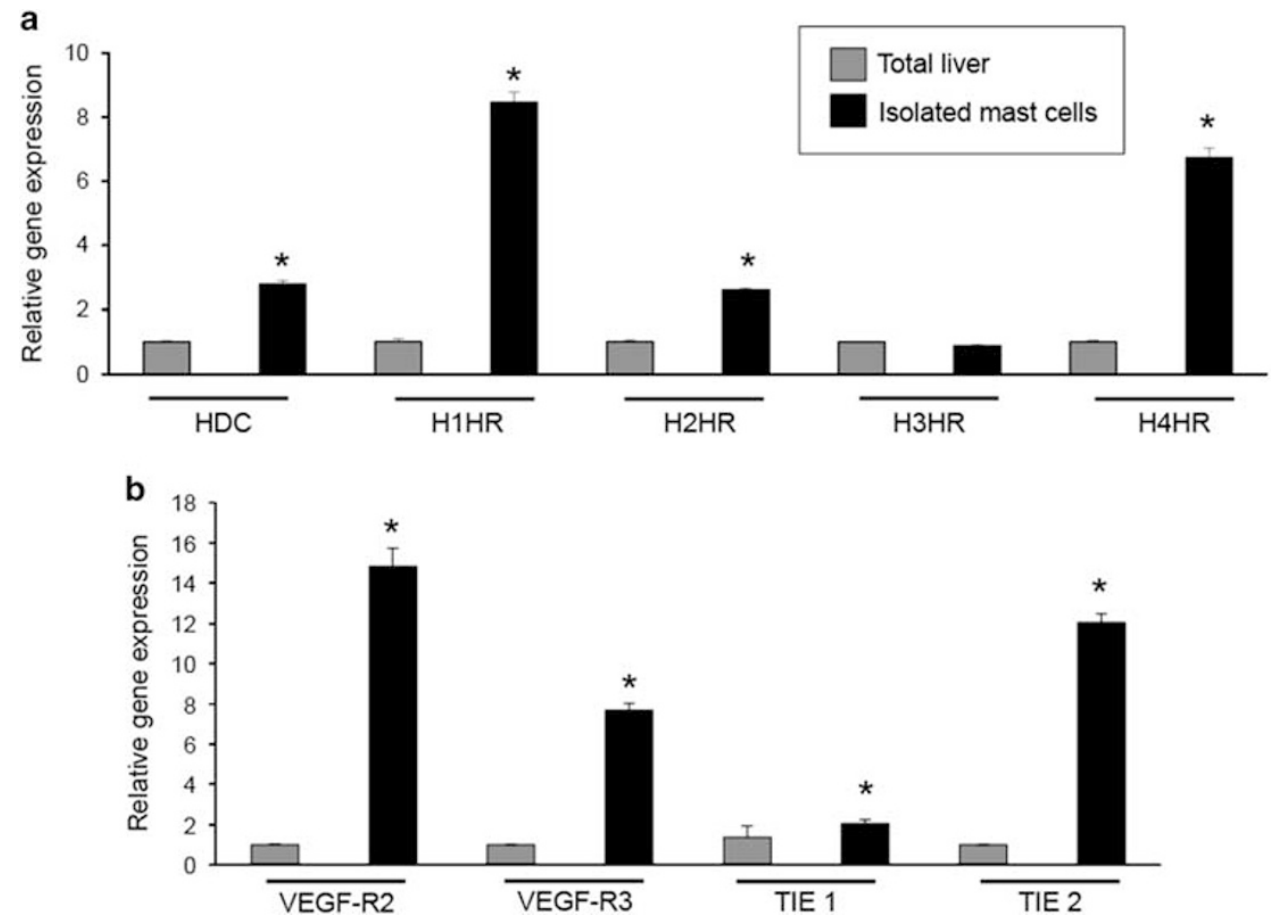

Figure 6 Characterization of isolated hepatic mast cells by real-time PCR for mast cell markers and other receptor ligands. Real-time PCR was performed in total liver and isolated mast cell preparations for HDC and the histamine receptors, H1-H4 HR (a) along with VEGF-R2, VEGF-R3, TIE 1, and TIE 2 (b). Isolated mast cells express significantly higher levels of mast cell markers, HDC, HRs (except H3HR), VEGF-R2, VEGF-R3, TIE 1, and TIE 2 when compared with total liver RNA. Data are represented as mean \pm s.e. of eight experiments. ${ }^{*} P<0.05$ versus total liver. HDC, histidine decarboxylase; HR, histamine receptor.

intact granules are found both within and outside of the membrane and are indicated by the red arrows.

Isolated mast cell populations were further verified by immunofluorescent staining for FCeR1, chymase, and tryptase as shown in Figure 5a. By real-time PCR, we found that isolated mast cells from rats with BDL 14 days expressed large amounts of mast cell markers including c-kit, FCeR1, chymase, tryptase, RMCP-I, and RMCP-II when compared with total liver RNA (Figure 5b).

Next, we examined our isolated mast cells for markers of histamine, VEGF, and angiopoietin receptors by real-time PCR. The expression of HDC, H1HR, H2HR, and H4HR are upregulated in isolated mast cell RNA compared with total liver (Figure 6a). There was no significant change in $\mathrm{H} 3 \mathrm{HR}$ between isolated mast cell RNA and total liver. Markers for VEGF-R2, VEGF-R3, TIE 1, and TIE 2 were increased in isolated mast cells compared with total liver, demonstrating that isolated hepatic mast cells have the machinery for the production of growth factors (Figure 6b).

Mast cells primarily contain histamine in their granules and, on activation, release large amounts of histamine. In addition, mast cells secrete many factors including VEGF. Histamine secretion is significantly increased in mast cell supernatants following T-STIM stimulation (to induce degranulation) when compared with un-stimulated cells (Figure 7a), whereas our isolated mast cells express VEGF receptors (Figure 6b), VEGF secretion was relatively unchanged in our isolated hepatic mast cell supernatants (Figure 7b).

To determine if our isolated mast cells are pure, we measured the expression of CK-19, albumin, CK-8, VAP-1, and $\alpha$-SMA in total liver and isolated mast cell RNA by realtime PCR. We found little to no expression (less than ' 1 ' in all genes evaluated) of these markers in our isolated mast cells when compared with total liver (Figure 8a). Further, the expression CK-19 (red) is absent in isolated mast cells as demonstrated by immunofluorescence for CK-19 and FCER1 (green) shown in Figure 8b. Similarly, the hepatocyte marker, CK-8 (red) is also absent in isolated mast cells shown by immunofluorescence (Figure 8c). Taken together, these results demonstrate that our isolated mast cells are virtually pure as they are void of other cellular markers.

\section{Mast Cell Infiltration in Other Liver Injury Models}

Hepatic mast cells were detected in various models of liver injury including $70 \% \mathrm{PH}, \mathrm{Mdr} 2^{-1-}$ mice and in human tissues from PSC patients. In Figure 9, toluidine blue-positive mast cells are found in normal rat liver following 70\% $\mathrm{PH}$ at 3 days (Figure 9a) and in normal rats fed bile acid, taurocholate for 1 week (Figure 9b). In human PSC, mast cells are present as indicated by the red arrows (Figure 9c). These data support the concept that mast cells infiltrate in models of rodent and human liver damage and injury and presumably play a role in these pathologies. 
a
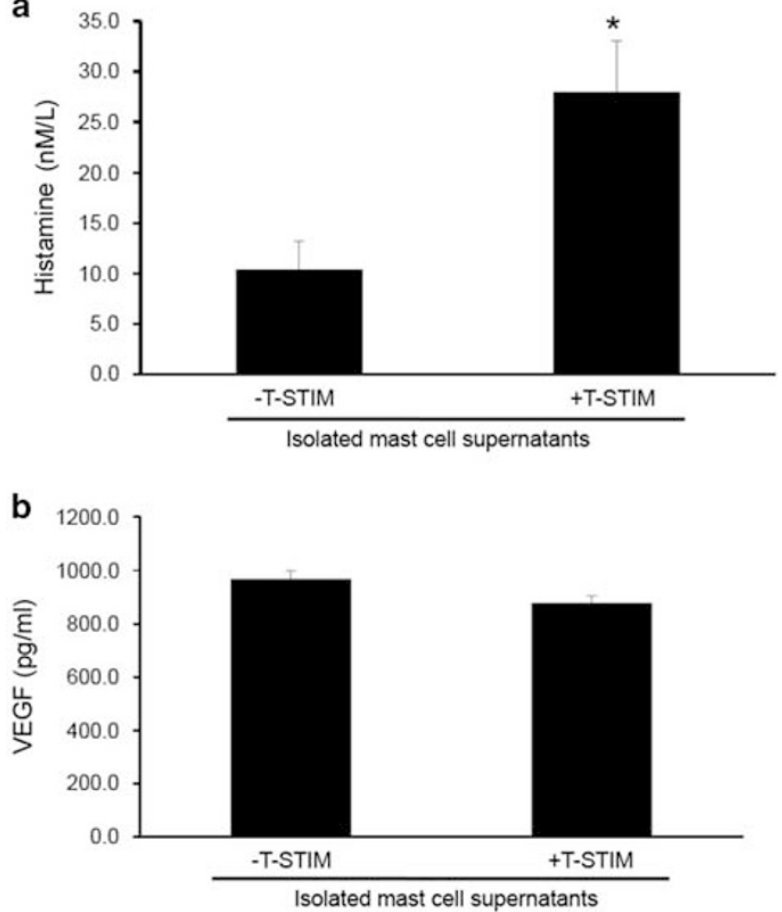

Figure 7 Evaluation of secretions released from mast cells by EIA. Isolated mast cells were incubated with T-stim to induce degranulation prior to the evaluation of histamine and VEGF-A. (a) Histamine release is increased in isolated mast cells stimulated with T-stim compared with unstimulated cells, whereas (b) VEGF-A levels are unchanged. Data are represented as mean \pm s.e. of 12 experiments. ${ }^{*} P<0.05$ versus $-\mathrm{T}$-stim. ElA, enzyme immuno-linked assay.

\section{Effect of Mast Cells on Cholangiocyte Proliferation In vitro}

To demonstrate that hepatic mast cells play a role in the biliary responses seen after liver injury, we examined the paracrine effect that mast cells and mast cell-derived histamine have on cholangiocyte proliferation and inflammation in vitro (Figure 10a). When cholangiocytes were stimulated with isolated mast cell supernatants collected from BDL 14 day rats treated with $\mathrm{NaCl}$, cholangiocyte proliferation and the expression of IL- 10 and TGF- $\beta 1$ significantly increased compared with untreated cholangiocytes (Figure 10b). However, when cholangiocytes were treated with isolated mast cell supernatants from BDL+cromolyn sodium rats (blocking mast cell-derived histamine release), biliary proliferation and pro-inflammatory cytokines were significantly decreased (Figure 10b), suggesting that mast cells and mast cell-derived histamine regulate biliary proliferation and response. To demonstrate that mast cell-derived histamine is critical to fibrosis progression, cultured HSCs were also treated with mast cell supernatants from BDL rats, which induced an increase in fibronectin, collagen type-1a, and $\alpha$-SMA gene expression. These markers were decreased when HSCs were stimulated with mast cell supernatants from $\mathrm{BDL}$ rats treated with cromolyn sodium, blocking mast cell-derived histamine (Figure 10c). These data strongly implicate mast cells in the regulation of biliary proliferation, inflammation and hepatic fibrosis.

\section{DISCUSSION}

Mast cells have notoriously been thought of as the 'allergymediating' cell that regulates the histaminergic responses when activated; however, it is now more recognized that mast cells contribute to a larger area of pathologies including liver diseases. ${ }^{24-26}$ To date, there are no protocols for the selection and isolation of mast cells from mature rodent livers. Our technique has been modified from established techniques used for isolating mast cells from fetal liver, peritoneal cavities, and bone marrow. ${ }^{18,19}$ Since our work and others have demonstrated that mast cells are found in the liver following injury or during repair, $, 1,8,12,14$ development of this tool is warranted and our technique successfully isolates mature hepatic mast cells.

Since mast cells are low in number in tissues during a homeostatic state, we induced injury to the liver by performing BDL at different time points starting at $6 \mathrm{~h}$ and up to 14 days. BDL induces ductal proliferation in response to the injured duct, ${ }^{20,27}$ and subsequently there is an infiltration of mast cells beginning $\sim 2-3$ days post BDL shown in Figure 1. In support of our findings, mast cells are also found in other models of liver injury and repair including following carbon tetrachloride treatment, ${ }^{28}$ alcohol feeding ${ }^{29}$ and during liver regeneration. ${ }^{30}$ Since mast cells do not mature and differentiate until they reach their tissue of destination, the contents of mast cells may differ between the liver and other organs. ${ }^{25}$ The hepatic mast cells that we have isolated from BDL rat livers are positive for both RMCP-I and RMCP-II, demonstrating that their origin is both mucosal and connective tissue derived. By PCR and immunofluorescence, we found that the isolated mast cells were void of PCs and NPC markers, as well as mesenchymal cell markers, demonstrating that these cells are a pure population of mast cells.

Mast cells typically migrate to the origin of a wound or damage therefore it is not surprising to see hepatic mast cells surrounding the reactive, proliferating bile ducts in rats following BDL. We did not detect mast cells in the periphery of the liver or around hepatocytes and this is consistent with other work demonstrating the presence of mast cells around bile ducts and vessel walls. ${ }^{7,11,31}$ The locality of mast cells is important to demonstrate since, on activation, they will release numerous preformed mediators and other components into the local tissue environment thus inducing a paracrine effect on the resident cell types. ${ }^{32}$ The paracrine effects of mast cell migration and activation has been demonstrated to occur via SCF-related signaling ${ }^{33}$ and our previous studies have shown that treatment with mast cell stabilizers like cromolyn sodium reduces the bile duct and cholangiocyte proliferative responses, thereby identifying 


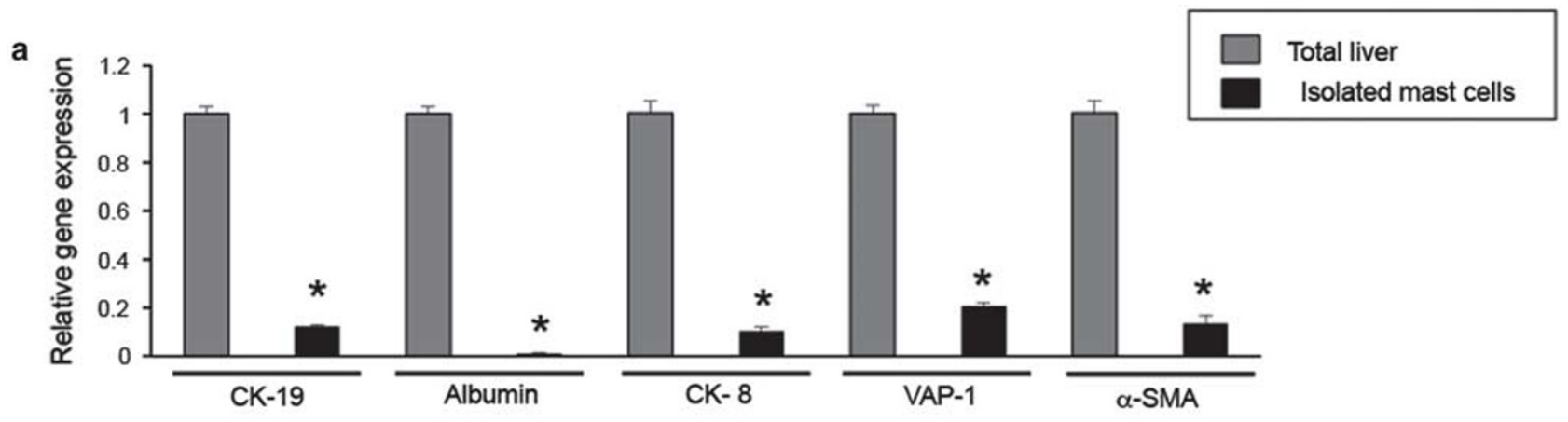

b

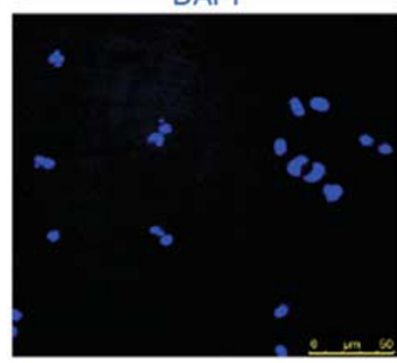

c

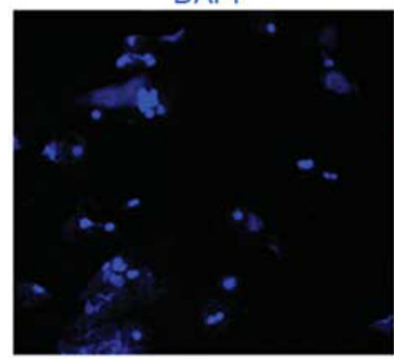

$\mathrm{FC}_{\varepsilon} \mathrm{R} 1$

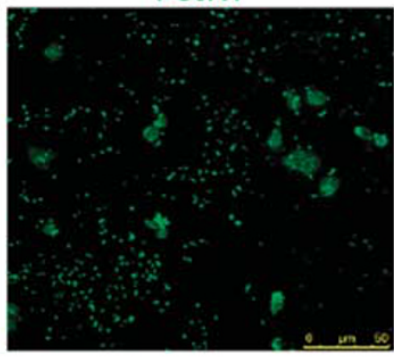

$\mathrm{FC} \varepsilon \mathrm{R} 1$

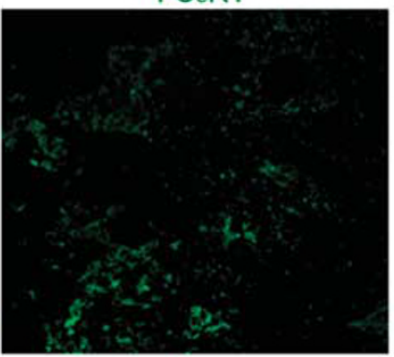

CK-19

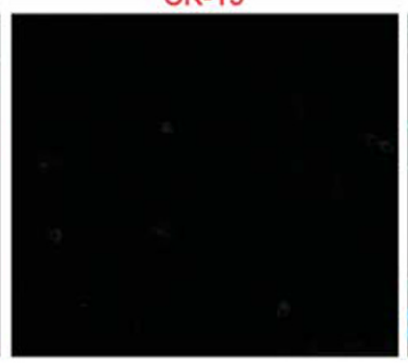

CK-8

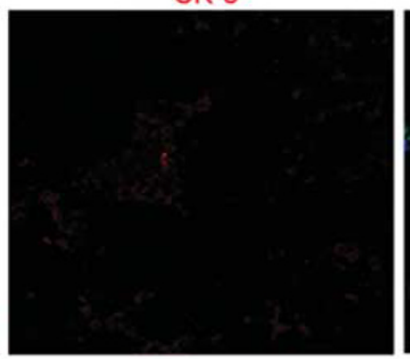

Merge

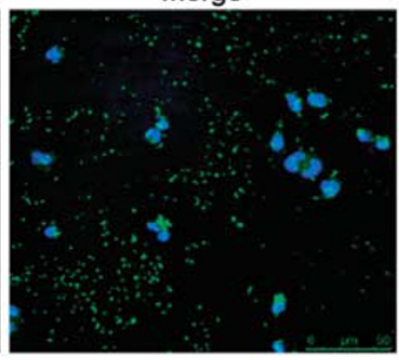

Merge

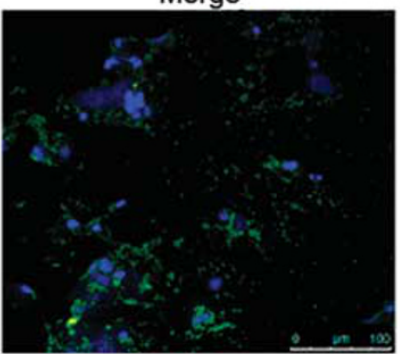

Figure 8 Measurement of parenchymal and non-parenchymal proteins. (a) The gene expression of CK-19, albumin, CK-8, VAP-1, and $a$-SMA was measured by real-time PCR. Isolated mast cells express very small amounts of these markers compared with total liver. (b) By immunofluorescence isolated mast cells were void of CK-19 and CK-8 protein. Cells were labeled for FCعR1 (green), CK-19 or CK-8 (red) and DAPI (blue). Data are represented as mean \pm s.e. of three experiments. ${ }^{*} P<0.05$ versus total liver. Images were obtained on a Leica Confocal Microscope and are $\times 20$ magnification.

mast cells as a paracrine regulator of cholangiocyte hyperplasia. ${ }^{14}$

The surface of mast cells is coated with numerous receptorbinding sites with FceR1 being the most abundant. ${ }^{26}$ Numerous studies have demonstrated that the surface of mast cells also contains receptors for growth factors and G-protein-coupled receptors, which on binding can induce the degranulation of mast cells. ${ }^{11,34}$ Our studies demonstrate that our isolated hepatic mast cells express typical mast cell markers including c-kit, FceR1, chymase, tryptase, and the histamine receptors $\mathrm{H} 1-\mathrm{H} 4$. In addition, we found nontraditional receptors including VEGF-R2/R3 and TIE 1/2, which is supported by studies demonstrating that other tissue-specific mast cells express these growth factor receptors. Human mast cells have been shown to express VEGF-A, VEGF-C, and VEGF-D along with VEGF receptor type 1 and 2. ${ }^{35,36}$ Further, in human mast cells, migration has been found to be TIE-1 mediated, and both basophils and mast cells express this receptor. ${ }^{37}$ In our study, we demonstrated that our isolation technique yields a relatively pure population of functionally active hepatic mast cells. To verify this, we measured the expression of several other typical liver cell markers including CK-19, CK-8, and $\alpha$-SMA that were highly upregulated in total liver (containing cholangiocytes, hepatocytes, sinusoidal cells, and hepatic stellate cells), but were almost void in the isolated mast cell RNA.

Mast cells are composed primarily of granules (seen in both Figures 3 and 4) that contain preformed mediators like histamine, serotonin, tryptase, and heparin. ${ }^{38}$ In addition, newly formed lipid mediators can also be released from mast cells including prostaglandin D2 and platelet-activating factor, as well as cytokines and chemokines. ${ }^{11,38}$ Many of these factors can induce paracrine alterations on the resident cells and tissue/organ response. The primary mediator released is histamine, which plays an important role in not only allergic responses, but also in liver diseases as we have previously 
a

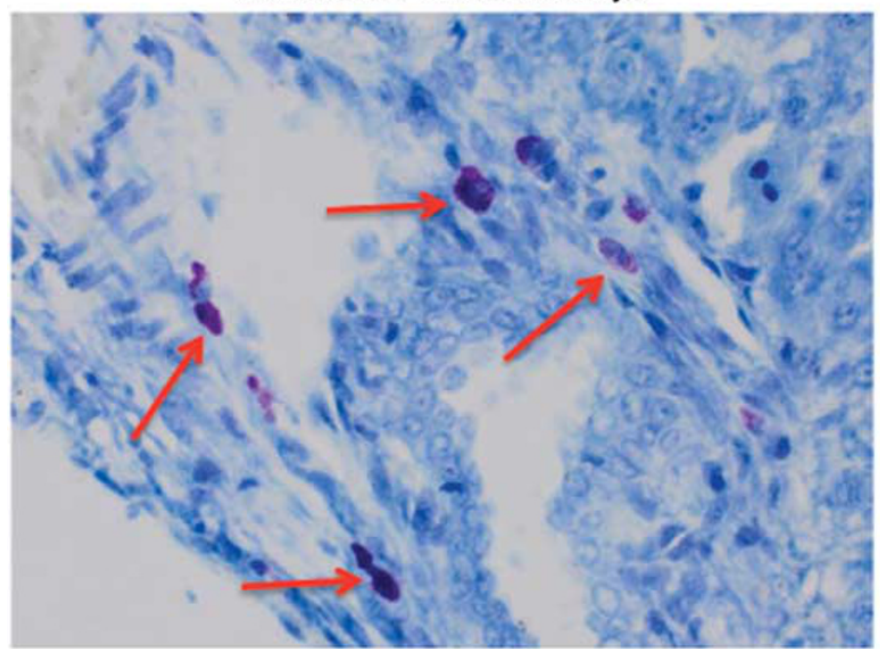

b

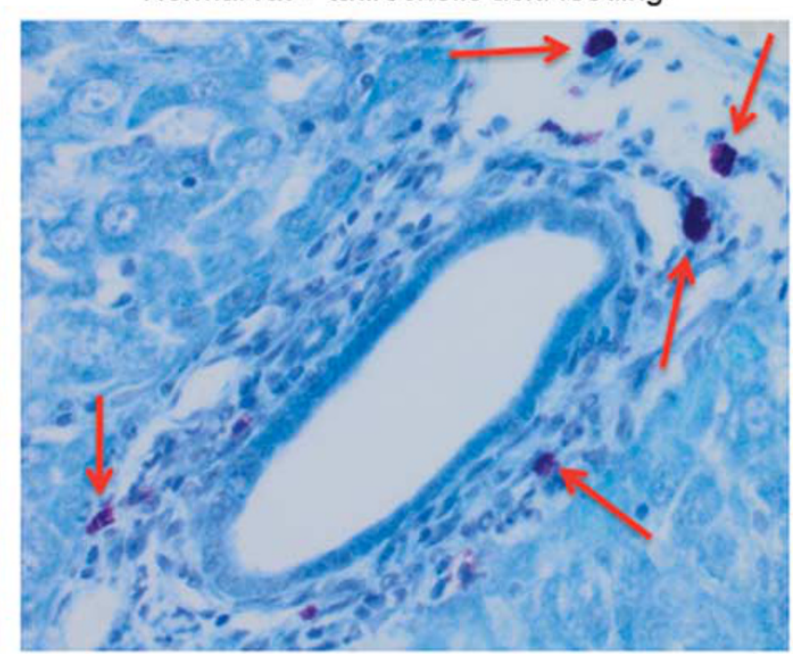

C

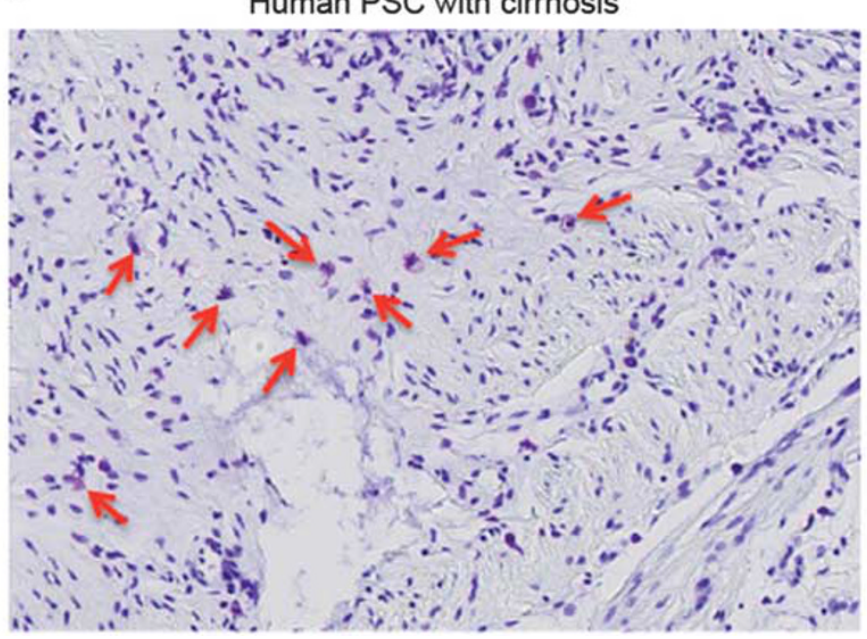

Figure 9 By toluidine blue and immunohistochemistry, we identified mast cells in other models of liver injury. (a) Toluidine blue-positive mast cells are found in the rat liver following 70\% PH (3 days) and in normal rats fed taurocholic acid for 1 week (b). (c) In livers from patients with PSC coupled with cirrhosis, mast cells are shown by toluidine blue staining. Red arrows mark mast cells. Images are $\times 20$ and $\times 10$ magnification.

demonstrated. ${ }^{12,14,15,17,20}$ Histamine is secreted in small amounts from cholangiocytes (that contain the machinery for histamine synthesis), which induces an autocrine regulation of hyperplastic and neoplastic growth. ${ }^{14,15,17}$ Here we found that our isolated mast cells release large amounts of histamine following degranulation with T-STIM; however, the levels of VEGF were unchanged in our isolated mast cells which was surprising since the expression of VEGF receptors was upregulated on isolated mast cells. While our isolated mast cells did not release VEGF, it has been shown that VEGF is secreted from bone marrow in vitro-derived mast cells when stimulated with IgE. ${ }^{39}$ Further, in human mast cells challenged with coricotropin-releasing hormone there was increased VEGF release. ${ }^{40}$ In our study, we challenged our mast cells with T-STIM to induce degranulation and our mast cells were taken ex vivo from rat livers, thus potentially explaining the differences in our findings. In support of this, it has been demonstrated that the contents of mast cells may differ between the liver and other organs, as well as compounds used to challenge mast cells. ${ }^{25}$

Hepatic mast cells can be found in numerous models of liver injury or repair. Besides our work demonstrating that mast cells infiltrate the liver following BDL and during cholangiocarcinoma progression, ${ }^{12,14}$ here we demonstrate that mast cells are present (i) during liver regeneration as shown in the 70\% PH model; (ii) in rats fed the bile acid, taurocholate for 1 week; and (iii) in liver sections from human PSC associated with cirrhosis. It has also been noted that mast cells may play a role in allograft rejection during liver resection or transplantation. In this study, the authors found that a crosstalk exists between mast cells and other cells including hepatocytes and induction of mast cell 
a

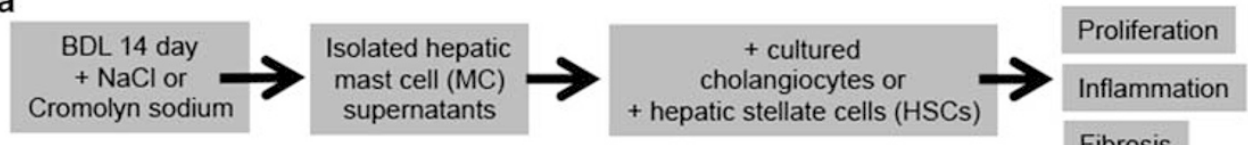

Cholangiocytes + 01\% BSA (basal)

Cholangiocytes + MC supernatant BDL 14 day $\mathrm{NaCl}$

Cholangiocytes + MC supernatant BDL 14 day cromolyn sodium

b
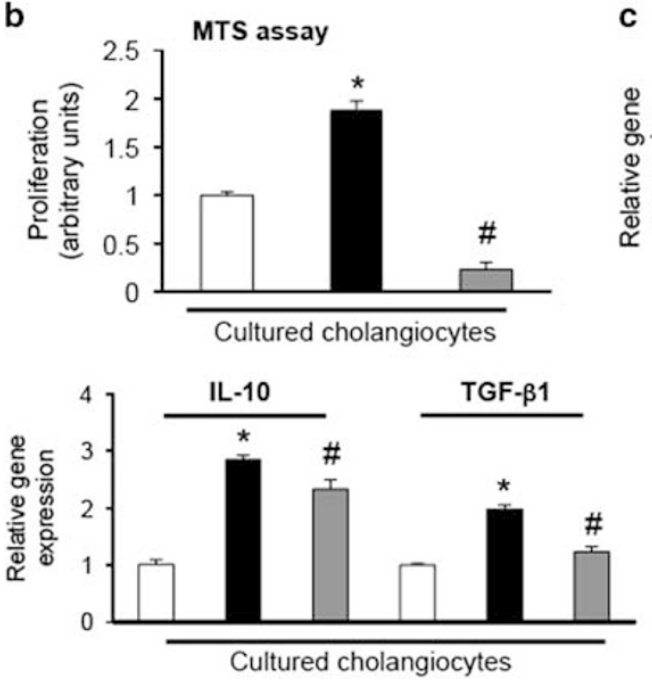

C
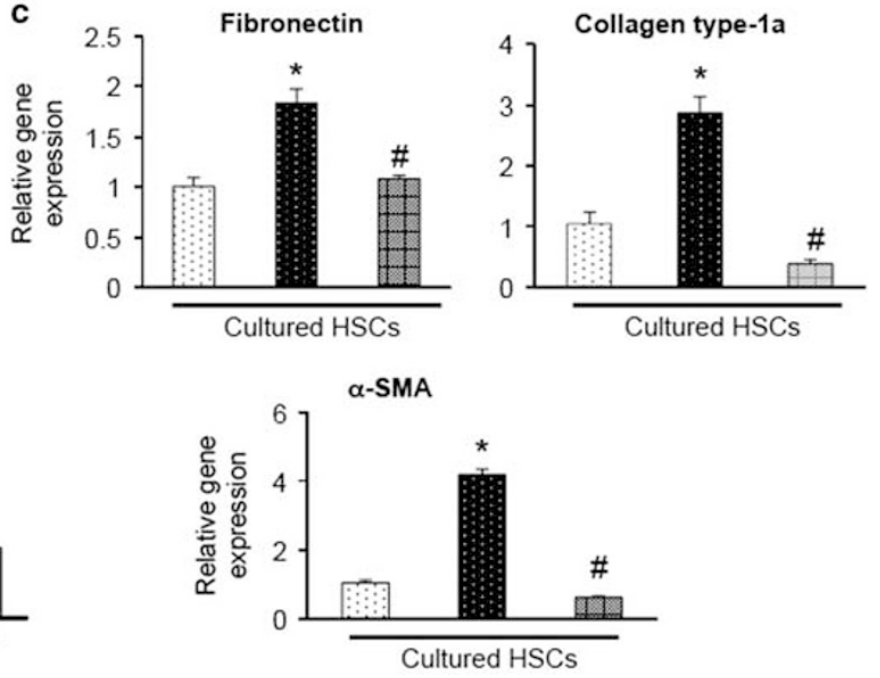

Figure 10 In vitro studies were performed in cultured cholangiocytes and hepatic stellate cells (HSCs). (a) Mast cells were isolated from BDL rats treated with saline or cromolyn sodium and supernatants were obtained. Cultured cholangiocytes or HSCs were then treated with $0.1 \%$ BSA (basal) or isolated mast cell supernatants from the two groups, and proliferation, inflammation, and fibrosis markers were measured. (b) Cholangiocyte proliferation, and IL-10 and TGF- $\beta 1$ expression increased following stimulation with isolated mast cell supernatants from BDL rats treated with NaCl compared with basal treatment, and in cholangiocytes stimulated with isolated mast cell supernatants from BDL rats treated with cromolyn sodium, biliary proliferation, and the pro-inflammatory cytokines were significantly decreased. (c) Fibrosis markers, fibronectin, collagen type-1a, and a-SMA expression were increased in HSCs following stimulation with isolated mast cell supernatants from BDL rats treated with $\mathrm{NaCl}$ compared with basal treatment and in HSCs stimulated with isolated mast cell supernatants from BDL rats treated with cromolyn sodium, fibronectin, collagen type-1a, and $a$-SMA were significantly decreased. Data are represented as mean \pm s.e. of six experiments for MTS assay and three experiments for real-time PCR. ${ }^{*} P<0.05$ versus $0.1 \%$ BSA, ${ }^{\#} P<0.05$ versus treatment with $\mathrm{MC}$ supernatant $\mathrm{BDL} 14$ day $\mathrm{NaCl}$. EIA, enzyme immuno-linked assay.

degranulation induces hepatocyte proliferation, thus contributing positively to cellular repopulation and liver regeneration. ${ }^{30}$ Similar to our findings, mast cells have been noted to increase in number during PSC progression ${ }^{7,33}$ in both rodent models and human tissues. In humans, increased SCF from cholangiocytes may induce infiltration of c-kitpositive mast cells inducing a paracrine stimulation of fibrosis-promoting cells. Further, mast cells may begin to synthesize and express fibrogenic factors such as TGF- $\beta$ thus promoting hepatic fibrosis. ${ }^{33}$ This work correlates with our study regarding mast cell infiltration into cholangiocarcinoma tumors via SCF/c-kit interactions. ${ }^{12}$ Taken together, mast cells should be considered as a relevant and important player in liver disease and progression.
Since we have demonstrated that mast cells infiltrate the liver following BDL and that treatment with cromolyn sodium decreases both mast cell infiltration and mast cell histamine release, we lastly set out to determine the direct effects of isolated mast cells on biliary proliferation and fibrosis. In cholangiocytes stimulated with mast cell supernatants collected from BDL rats treated with $\mathrm{NaCl}$, biliary proliferation increased significantly compared with untreated cholangiocytes. More interestingly, when cholangiocytes were treated with mast cell supernatants collected from BDL rats treated with cromolyn sodium these factors decrease, suggesting that mast cell-derived histamine directly contributes to the proliferative response of cholangiocytes. Further, we found that HSCs were also altered by stimulation with 
isolated mast cell supernatants. Specifically, HSC collagen content and fibronectin expression is decreased following treatment with mast cell supernatants from BDL rats treated with cromolyn sodium compared with HSCs stimulated with mast cells from BDL rats treated with $\mathrm{NaCl}$. This data is supported by the findings from Tsuneyama et $a l^{33}$ showing that mast cells induce fibrogenic factors. In addition, an in vitro study has demonstrated that when HSCs were treated with cromolyn sodium there was a significant reduction in collagen accumulation and TGF- $\beta$-associated EMT and hepatocyte senescence, suggesting that cromolyn sodium may be a strong therapeutic target for liver fibrosis and cirrhosis. ${ }^{41}$

In summary, we have developed a technique to isolate a pure population of hepatic mast cells from rat livers that are functionally active. It is becoming increasingly evident that mast cells are key regulators and target cells in a number of cholangiopathies and fibrotic-driven pathologies within the liver. Thus, this protocol will enhance our study and evaluation of the effects that mast cells induce in liver diseases. Further, by using this technique we can fully investigate the paracrine role that mast cells play during liver disease along with their potential effects on other liver cell types including cholangiocytes and hepatic stellate cells, as we have shown in our study. This could be taken further to also study the role of mast cells with regard to hepatocytes or vascular and sinusoidal endothelial cells. Since it is not completely understood if infiltrated mast cells in the liver are 'good' or 'bad' cells, this tool will enable our future studies to answer this question and increase our knowledge of the functional role that mast cells play during hepatic disease progression.

Supplementary Information accompanies the paper on the Laboratory Investigation website (http://www.laboratoryinvestigation.org)

\section{ACKNOWLEDGMENTS}

Portions of this work were supported by (i) a VA Merit Award (1101BX003031) from the US Department of Veteran's affairs, Biomedical Laboratory Research and Development Service and an RO1 from NIH NIDDK (1R01DK108959) (HF); (i) funds from the PSC Partners Seeking a Cure (HF); (ii) a Scott and White Research Mentor Award (HF); and (iii) the Dr Nicholas C. Hightower Centennial Chair of Gastroenterology from Scott \& White Health. This research was supported in part by the Veterans Health Administration. The contents do not represent the views of the US Department of Veterans Affairs or the United States Government.

\section{DISCLOSURE/CONFLICT OF INTEREST}

The authors declare no conflict of interest.

1. Machado MV, Diehl AM. Pathogenesis of nonalcoholic steatohepatitis. Gastroenterology 2016;150:1769-1777.

2. Tanimizu N, Mitaka T. Morphogenesis of liver epithelial cells. Hepatol Res 2016;3:1-13.

3. Alpini G, Prall RT, LaRusso NF. The pathobiology of biliary epithelia. In: Arias 4EIM, Boyer JL, Chisari FV et al. (eds). The Liver; Biology \& Pathobiology. Lippincott Williams \& Wilkins: Philadelphia, PA, USA, 2001;421-435.

4. Lazaridis KN, LaRusso NF. The cholangiopathies. Mayo Clin Proc 2015;90:791-800.
5. O'Hara SP, Tabibian JH, Splinter PL, et al. The dynamic biliary epithelia: molecules, pathways, and disease. J Hepatol 2013;58:575-582.

6. Farrell $\mathrm{DJ}$, Hines JE, Walls $\mathrm{AF}$, et al. Intrahepatic mast cells in chronic liver diseases. Hepatology 1995;22:1175-1181.

7. Ishii $M$, Iwai $M$, Harada $Y$, et al. A role of mast cells for hepatic fibrosis in primary sclerosing cholangitis. Hepatol Res 2005;31:127-131.

8. Satomura K, Yin M, Shimizu S, et al. Increased chymase in livers with autoimmune disease: colocalization with fibrosis. J Nippon Med Sch 2003;70:490-495.

9. Ranieri G, Ammendola M, Patruno R, et al. Tryptase-positive mast cells correlate with angiogenesis in early breast cancer patients. Int J Oncol 2009;35:115-120.

10. Hakim-Rad K, Metz M, Maurer M. Mast cells: makers and breakers of allergic inflammation. Curr Opin Allergy Clin Immunol 2009;9:427-430.

11. Halova I, Draberova L, Draber P. Mast cell chemotaxis - chemoattractants and signaling pathways. Front Immunol 2012;3:119.

12. Johnson $C$, Huynh V, Hargrove $L$, et al. Inhibition of mast cell-derived histamine decreases human cholangiocarcinoma growth and differentiation via c-Kit/stem cell factor-dependent signaling. Am J Pathol 2016;186:123-133.

13. Gaudio E, Barbaro B, Alvaro D, et al. Vascular endothelial growth factor stimulates rat cholangiocyte proliferation via an autocrine mechanism. Gastroenterology 2006;130:1270-1282.

14. Kennedy LL, Hargrove LA, Graf AB, et al. Inhibition of mast cell-derived histamine secretion by cromolyn sodium treatment decreases biliary hyperplasia in cholestatic rodents. Lab Invest 2014;94:1406-1418.

15. Francis $\mathrm{H}$, DeMorrow S, Venter $\mathrm{J}$, et al. Inhibition of histidine decarboxylase ablates the autocrine tumorigenic effects of histamine in human cholangiocarcinoma. Gut 2012;61:753-764.

16. Gittlen SD, Schulman ES, Maddrey WC. Raised histamine concentrations in chronic cholestatic liver disease. Gut 1990;31:96-99.

17. Francis $\mathrm{HL}$, DeMorrow $\mathrm{S}$, Franchitto $\mathrm{A}$, et al. Histamine stimulates the proliferation of small and large cholangiocytes by activation of both IP $\left({ }_{3}\right) / \mathrm{Ca}\left({ }^{2+}\right)$ and CAMP-dependent signaling mechanisms. Lab Invest 2012;92:282-294.

18. Jamur MC, Grodzki AC, Moreno AN, et al. Identification and isolation of rat bone marrow-derived mast cells using the mast cell-specific monoclonal antibody AA4. J Histochem Cytochem 2001;49:219-228.

19. Jamur MC, Grodzki AC, Moreno AN, et al. Immunomagnetic isolation of rat bone marrow-derived and peritoneal mast cells. J Histochem Cytochem 1997;45:1715-1722.

20. Francis $H$, Franchitto $A$, Ueno $Y$, et al. $H 3$ histamine receptor agonist inhibits biliary growth of BDL rats by downregulation of the CAMPdependent PKA/ERK1/2/ELK-1 pathway. Lab Invest 2007;87:473-487.

21. Ribatti $D$, Guidolin $D$, Marzullo $A$, et al. Mast cells and angiogenesis in gastric carcinoma. Int J Exp Pathol 2010;91:350-356.

22. Lesage G, Glaser SS, Gubba S, et al. Regrowth of the rat biliary tree after $70 \%$ partial hepatectomy is coupled to increased secretin-induced ductal secretion. Gastroenterology 1996;111:1633-1644.

23. Mancinelli $R$, Onori $P$, Gaudio $E$, et al. Taurocholate feeding to bile duct ligated rats prevents caffeic acid-induced bile duct damage by changes in cholangiocyte VEGF expression. Exp Biol Med (Maywood) 2009;234:462-474.

24. Bachelet I, Levi-Schaffer F, Mekori YA. Mast cells: not only in allergy. Immunol Allergy Clin North Am 2006;26:407-425.

25. Beaven MA. Our perception of the mast cell from Paul Ehrlich to now. Eur J Immunol 2009;39:11-25.

26. Boyce JA. Mast cells: beyond IgE. J Allergy Clin Immunol 2003;111:24-32.

27. Marzioni $\mathrm{M}$, Glaser SS, Francis $\mathrm{H}$, et al. Functional heterogeneity of cholangiocytes. Semin Liver Dis 2002;22:227-240.

28. Akiyoshi H, Terada T. Mast cell, myofibroblast and nerve terminal complexes in carbon tetrachloride-induced cirrhotic rat livers. J Hepatol 1998;29:112-119.

29. Wimberly AL, Forsyth CB, Khan MW, et al. Ethanol-induced mast cellmediated inflammation leads to increased susceptibility of intestinal tumorigenesis in the APC Delta468 min mouse model of colon cancer. Alcohol Clin Exp Res 2013;37:E199-E208.

30. Nakano T, Lai CY, Goto S, et al. Immunological and regenerative aspects of hepatic mast cells in liver allograft rejection and tolerance. PLoS One 2012;7:e37202.

31. Koda W, Harada K, Tsuneyama K, et al. Evidence of the participation of peribiliary mast cells in regulation of the peribiliary vascular plexus along the intrahepatic biliary tree. Lab Invest 2000;80:1007-1017. 
32. Lorentz A, Sellge G, Bischoff SC. Isolation and characterization of human intestinal mast cells. Methods Mol Biol 2015;1220:163-177.

33. Tsuneyama $\mathrm{K}$, Kono $\mathrm{N}$, Yamashiro $\mathrm{M}$, et al. Aberrant expression of stem cell factor on biliary epithelial cells and peribiliary infiltration of c-kit-expressing mast cells in hepatolithiasis and primary sclerosing cholangitis: a possible contribution to bile duct fibrosis. J Pathol 1999;189:609-614.

34. Hugle $T$, Hogan $V$, White $K E$, et al. Mast cells are a source of transforming growth factor beta in systemic sclerosis. Arthritis Rheum 2011;63:795-799.

35. Detoraki A, Staiano Rl, Granata F, et al. Vascular endothelial growth factors synthesized by human lung mast cells exert angiogenic effects. J Allergy Clin Immunol 2009;123:1142-1149.

36. Marone G, Varricchi G, Loffredo $S$, et al. Mast cells and basophils in inflammatory and tumor angiogenesis and lymphangiogenesis. Eur J Pharmacol 2015;778:146-151.
37. Prevete N, Staiano Rl, Granata F, et al. Expression and function of Angiopoietins and their tie receptors in human basophils and mast cells. J Biol Regul Homeost Agents 2013;27:827-839.

38. Boyce JA. The biology of the mast cell. Allergy Asthma Proc 2004;25: 27-30.

39. Boesiger J, Tsai $M$, Maurer $M$, et al. Mast cells can secrete vascular permeability factor/ vascular endothelial cell growth factor and exhibit enhanced release after immunoglobulin E-dependent upregulation of fc epsilon receptor I expression. J Exp Med 1998;188:1135-1145.

40. Asadi S, Theoharides TC. Corticotropin-releasing hormone and extracellular mitochondria augment IgE-stimulated human mast-cell vascular endothelial growth factor release, which is inhibited by luteolin. J Neuroinflammation 2012;9:85.

41. Choi JS, Kim JK, Yang YJ, et al. Identification of cromolyn sodium as an anti-fibrotic agent targeting both hepatocytes and hepatic stellate cells. Pharmacol Res 2015;102:176-183. 